\title{
Intergenerational Similarities in Risk Factors for Offending
}

\author{
David P. Farrington • Maria M. Ttofi • \\ Rebecca V. Crago • Jeremy W. Coid
}

Received: 11 November 2014 / Revised: 17 February 2015 / Accepted: 17 February 2015 /

Published online: 10 March 2015

(C) Springer International Publishing AG 2015

\begin{abstract}
Purpose The main aim of this article is to investigate to what extent the relationships between risk factors and offending by males are similar from one generation to the next.

Methods The Cambridge Study in Delinquent Development is a prospective longitudinal survey of 411 London males who were originally studied at age 8 . This article compares these males (generation 2 or G2) with their biological parents (generation 1 or G1) and biological children (generation 3 or G3). Ninety-four per cent of G2 males were interviewed at age 32 , while $85 \%$ of G3 males were interviewed at an average age of 25.

Results Up to age 21, $34 \%$ of G2 males were convicted, compared with $20 \%$ of G3 males. Eleven risk factors were significant predictors of both G2 and G3 offending: a convicted father and mother, harsh discipline, poor parental supervision, a disrupted family, low family income, large family size, poor housing, low school attainment, daring/risk-taking and antisocial child behaviour. The findings were markedly different for only three risk factors: parental conflict, low social class and hyperactivity/attention problems. Over 20 risk factors, G2 effect sizes correlated .80 with G3 effect sizes.

Conclusions $\mathrm{G} 2$ results were similar to $\mathrm{G} 3$ results. While risk factors were not exactly comparable between generations, most of the findings in one generation were replicated in the next generation.
\end{abstract}

Keywords Risk factors · Offending · Intergenerational $\cdot$ Longitudinal

D. P. Farrington $(\bowtie) \cdot$ M. M. Ttofi $\cdot$ R. V. Crago

Institute of Criminology, Cambridge University, Sidgwick Avenue, Cambridge CB3 9DA, UK

e-mail: dpf1@cam.ac.uk

J. W. Coid

Violence Prevention Research Unit, Wolfson Institute of Preventive Medicine,

Queen Mary University of London, Garrod Building, Turner St., London E1 2AD, UK 


\section{Introduction}

A key issue in criminology is to what extent are risk factors for offending similar over time and place? This question has rarely been investigated, despite the classic book on Historical and Geographical Influences on Psychopathology [6]. It concerns the strength of the relationship between risk factors and offending, not the prevalence, level or magnitude of risk factors. For example, numerous childhood (age 8-10) risk factors for offending (especially measured by convictions) have been identified in the Cambridge Study in Delinquent Development (CSDD), which is a prospective longitudinal study of 411 London boys born mostly in 1953 (see later). To what extent can these results be generalized to other times and places? For example, broken homes have increased in the UK since the 1960s, and family size has decreased. Nevertheless, are the relationships between broken homes and offending, and between large family size and offending, similar for the next generation, and specifically for the children of the original 411 males?

The importance of historical context was emphasized by Elder [8]. He stated (p.2) that "historical forces shape the social trajectories of family, education, and work, and they in turn influence behavior and particular lines of development". He also emphasized the importance of life events and life transitions (e.g. early childbearing and joining the military) on development. Cohen et al. [6], in their Preface (pp. ix-x), argued that, if incidence rates are stable across time and place, this suggests that biological factors are more important than environmental factors. If incidence rates vary over time, researchers should focus on historical events as possible explanations. If incidence rates vary across nations or cultural groups, researchers should focus on risk factors that differ across these groups.

In order to investigate the replicability of risk factors for delinquency over time and place, Farrington and Loeber [20] compared results in the CSDD for the 411 boys aged 8-10 in 1961-1963 with results in the Pittsburgh Youth Study (PYS) for 508 boys aged 10 in 1987-1988. Efforts had been made to measure risk factors in the later survey that were comparable to those measured in the earlier survey. In both cases, the strength of relationships between childhood risk factors (usually dichotomized, for comparability, into the "worst" quarter vs the remainder), and court appearances for delinquency between ages 10 and 16, were compared. They found that most childhood risk factors were similarly related to delinquency in the 1960s in London and in the 1990s in Pittsburgh.

This article compares risk factors for offending in two successive generations. To a large extent, it focusses on changes over time and holds constant other (e.g. geographical) influences. In studying risk factors in successive generations, it is important to have comparable measures. It is also important to measure risk factors prospectively, in order to avoid retrospective bias. Most early studies of intergenerational transmission (at least up to the special section of Developmental Psychology edited by Serbin and Stack [37]) compared retrospective reports in one generation with prospective reports in the next generation.

By the time of the next special section on intergenerational transmission, in the Journal of Abnormal Child Psychology edited by Capaldi et al. [4], most of the articles 
were based on prospective reports in successive generations. The major studies by Capaldi et al. [5] in Oregon and Thornberry et al. [39] in Rochester investigated the intergenerational transmission of antisocial behaviour and the extent to which it was mediated by parental and other (e.g. socio-economic) risk factors. Later special sections (e.g. [2]) and special issues (e.g. [3]) also focussed on mediating factors that might explain intergenerational transmission. For example, Bailey et al. [1] in Seattle and Farrington et al. [16] in the CSDD investigated the extent to which family risk factors mediated the intergenerational transmission of antisocial behaviour and offending.

We have not found any prospective longitudinal study that explicitly compared risk factors with offending in successive generations. This requires a three-generation study, since family risk factors in generation 1 need to be compared with children's offending in generation 2, and family risk factors in generation 2 need to be compared with children's offending in generation 3. The most relevant studies are probably those by Menard and Johnson [34] and Johnson et al. [31]. Both analysed the National Youth Survey-Family Study to investigate the extent to which particular theories of offending were applicable in successive generations. Menard and Johnson [34] tested the applicability of the integrated theory proposed by Elliott et al. [9]. They found that the most important risk factor in both generations was delinquent peer bonding but that school strain (low grades and low academic expectations) was more important for the second generation. Johnson et al. [31] tested the importance of general strain theory in two generations and concluded that strain variables (e.g. low expectations of getting a good job and graduating from college) were directly related to delinquency in both generations.

The present article examines the replicability of risk factors for offending in three successive generations in the CSDD: the original 411 boys, their biological parents and their biological children. The original boys are called generation 2 (G2), while their biological parents are generation $1(\mathrm{G} 1)$, and their biological children are generation 3 (G3). This article compares parental, family and socio-economic risk factors in G1 with offending by G2, and parental, family and socio-economic risk factors in G2 with offending by G3. It also compares childhood individual (attainment, impulsiveness and behavioural) risk factors in G2 with later offending by G2, and similar individual risk factors in G3 with offending by G3.

A great deal is known about the most important childhood risk factors for offending by the G2 males (e.g. [17]). These include parental and family factors such as a convicted parent, poor parental supervision and a disrupted family; socio-economic factors such as low family income, poor housing, and large family size; individual factors such as low intelligence, low school attainment, high daring/risk-taking and hyperactivity/poor concentration; and behavioural factors such as troublesomeness and dishonesty. The main aim in this article is to measure, as far as possible, similar risk factors in the next generation and to compare them with offending by the G3 males. In both generations, the strength of relationships between dichotomized risk factors and dichotomized convictions is measured using the odds ratio (OR). As far as possible, risk factors and offending are measured at the same ages. The independently important predictors are assessed using forward stepwise logistic regression analyses. 


\section{Method}

\section{The CSDD}

As mentioned, the CSDD is a prospective longitudinal survey of the development of offending and antisocial behaviour in 411 London males from age 8 onwards. The CSDD began in 1961, and for the first 20 years, it was directed by Donald West. David Farrington started working on it in 1969 and began directing the CSDD in 1982. The most recent data collections have been jointly directed by David Farrington and Jeremy Coid. Results of the Study have been described in six books [22, 36, 40-43], and in five summary articles $[11,12,17,25,26]$. These works should be consulted for more information about the CSDD.

At the time they were first contacted in 1961-1962, the G2 boys were all living in a working-class area of South London. The vast majority of the sample was chosen by taking all the boys who were then aged 8-9 and on the registers of six state primary schools within a $1-\mathrm{mi}(1.6 \mathrm{~km})$ radius of a research office which had been established. In addition to 399 boys from these six schools, 12 boys from a local school for educationally subnormal children were included in the sample, in an attempt to make it more representative of the population of boys living in the area. Therefore, the boys were not a probability sample drawn from a population, but rather a complete population of boys of that age in that area at that time.

Most of the G2 boys (357, or $87 \%$ ) were Caucasian in appearance and of British origin, in the sense that they were being brought up by parents who had themselves been brought up in England, Scotland, or Wales. Of the remaining 54 boys, 12 were Afro-Caribbean, having at least one parent of West Indian (usually) or African origin. Of the remaining 42 boys of non-British origin, 14 had at least one parent from the North or South of Ireland, 12 had parents from Cyprus, and the other 16 boys were Caucasian and had at least one parent from another Western industrialized country.

On the basis of their fathers' occupations when they were aged 8, $94 \%$ of the G2 boys could be described as working class (categories III, IV or V on the Registrar General's scale, describing skilled, semi-skilled or unskilled manual workers), in comparison with the national figure of $78 \%$ at that time. The majority of the boys were living in conventional two-parent families with both a father and a mother figure; at age 8 , only $6 \%$ of the boys had no operative father and only $1 \%$ had no operative mother. This was, therefore, overwhelmingly a traditional Caucasian, urban, workingclass sample of British origin.

\section{Interviews}

The G2 males have been interviewed nine times, at ages 8, 10, 14, 16, 18, 21, 25, 32 and 48. At all ages except 21 and 25, the aim was to interview all the G2 males who were still alive, and it was always possible to interview a high proportion: 405 (99\%) at age 14, $399(97 \%)$ at age 16, $389(95 \%)$ at age 18, $378(94 \%)$ at age 32 and 365 
$(93 \%)$ at age 48 . The main focus in this article is on the information collected at age 32 , when most of the G3 children were under age 10 .

Between 2004 and 2013, efforts were made to interview the biological children of the G2 males. These interviews were carried out over a 9-year period because of intermittent funding. There were $691 \mathrm{G} 3$ children whose name and date of birth were known. Only children aged at least 18 (born up to 1995) were targeted. The ethical requirements of the South-East Region Medical Ethics Committee required that we contact the G2 male and/or his female partner in trying to interview the G3 children and that we only interview G3 children aged at least 18 . Twenty children whose fathers refused at age 48, and 7 children whose father was dead at age 48 (and where no female partner was available) were not eligible to be interviewed. An additional six G3 males who had died and three who were disabled (one Down's syndrome, one mental health problems, one severe attention deficit-hyperactivity disorder), together with two who did not know that the G2 male was their father, were considered to be not eligible. Of the 653 eligible G3 children, 551 were interviewed (84.4\%) at an average age of 25 , including 291 of the $343 \mathrm{G} 3$ males $(84.8 \%$ ) and 260 of the $310 \mathrm{G} 3$ females $(83.9 \%)$. Of the remainder, 39 children refused, 33 parents refused, 13 children could not be traced, 14 were elusive (agreeing or not refusing but never being available to interview), and 3 were aggressive or problematic. Of the 29 children living abroad, 17 were interviewed, usually by telephone.

\section{Criminal Record Searches of the G2 Males}

These searches have been described in previous publications (e.g. [14, 19]). The minimum age of criminal responsibility in England and Wales is 10. Recent searches of criminal records of the G2 males took place in July 2002 and December 2004 in the Police National Computer (PNC), at which time most of the males were aged 51. The Home Office report [15] and many previous analyses were based on the criminal records up to age 50 derived from these searches. A further search of the PNC was completed in March 2011, when most males were aged 57. The criminal records of the G2 males are therefore now known up to age 56 [22].

For comparability with the G3 children, it was recently decided to count officially recorded cautions as well as convictions in the PNC, since cautions were routinely recorded on a national basis from 1995 [24]. In total, 177 G2 males were convicted up to age 56 ( $43.8 \%$ of 404 at risk) for a total of 909 offences, including 51 cautions. In this article, "convictions" include cautions. Convictions were only counted if they were for "standard list" (more serious) offences, thereby excluding minor crimes such as minor traffic infractions and simple drunkenness. The most common offences included were thefts, burglaries and unauthorized takings of vehicles, although there were also quite a few offences of violence, vandalism, fraud and drug use. The definition of what is a "standard list" offence changed over time. In particular, common assault became a standard list offence in July 1995, drunk driving was added to the standard list from January 1996, and being drunk and disorderly was added in April 1997. All of these types of offences were counted. 


\section{Criminal Record Searches of the G3 Children}

As mentioned, there were 691 children whose name and date of birth were known. Their median year of birth was 1981, and more than half were born between 1977 and 1985. They were first searched in the microfiche records in 1994, and they were then searched in the PNC in 2003, 2006, and 2011-2012. The median age at which they were last searched was 30, and more than half were last searched between ages 25 and 33. The 29 G3 children who were abroad could not be searched, but 658 of the remaining 662 were searched. (In the other four cases, the identity of the convicted person was not clear.) These included 344 G3 males and 314 G3 females. The focus in this article is on the G3 males. Nearly all G3 males were searched up to age 21 at least, and $70(20.3 \%)$ were convicted up to age 21 . For comparison, 137 out of $404 \mathrm{G} 2$ males at risk $(33.9 \%)$ were convicted up to age 21 (excluding 7 males who emigrated before age 21 and were not searched abroad). It is known that the probability of conviction has decreased over time in England and Wales (see e.g. [18]).

\section{Age 8-10 G1 Risk Factors for G2 Male Offending}

For comparability, all risk factors were dichotomized, as far as possible, into the "worst" quarter versus the remainder (see [21]).

Parental Convictions of the G1 father and G1 mother up to age 32 were obtained from criminal record searches. (Age 32 was chosen for comparability in different generations.) Authoritarian attitudes to parenting by G1 fathers and G1 mothers were based on the Parental Attitude Schedules created by Gibson [27]. Example items are "Strict discipline develops a good strong character in children" and "Children who are made to obey will thank their parents later". Young G1 mothers were those who had their first child before age 21, and young G1 fathers were those who had their first child before age 23 . These ages were also chosen for comparability across generations. Nervousness of the G1 father was based on social worker ratings and psychiatric treatment. Nervousness of the G1 mother was based on both of these measures together with the Mother's Health Questionnaire [28].

Family Uninvolved G1 fathers were identified by a questionnaire on the extent to which the G1 father joined in the G2 boy's leisure activities (see [10, 38, 42], for more information about all G1 and G2 measures). The uninvolved G1 fathers rarely or never joined in the G2 boy's leisure activities. Harsh attitude and discipline at age 8-10 was based on social worker assessments of both G1 parents, as was poor parental supervision, which referred to the extent to which the G1 parents knew what the G2 boy was doing when he was out. Parental conflict was also rated by the social workers based on their interviews with the G1 parents, and it referred to chronic tension or disagreement in many fields, raging conflicts or estrangement. A disrupted family referred to the temporary or permanent separation from a G1 parent before the G2 boy's tenth birthday for reasons other than death or hospitalization. 
Socio-economic Low G1 family income at age 8 was rated by the social workers. Large family size referred to five or more children born to the G2 boy's mother up to his tenth birthday. Poor housing was rated by the social workers and referred to living in dilapidated slum premises. Low social class referred to G1 fathers who had an unskilled manual job when the $\mathrm{G} 2$ boy was age $8-10$.

Attainment Low nonverbal IQ (90 or less) of the G2 boy was measured by the Progressive Matrices test, while low verbal IQ was based on verbal comprehension and vocabulary tests, all completed at ages 8 and 10. Low junior school attainment of the G2 boy was based on school records of arithmetic, English and verbal reasoning tests completed by the $\mathrm{G} 2$ boys at age 10-11.

Impulsiveness High daring was rated by parents and peers and identified G2 boys who took many risks in traffic, climbing, exploring, etc. High impulsivity was based on the G2 boy's scores on three psychomotor tests, the Porteus Maze, the Spiral Maze, and the Tapping test. High hyperactivity was based on ratings by teachers of whether the G2 boy lacked concentration or was restless in class (at ages 8 and 10).

Behaviour High troublesomeness was rated by peers and teachers and identified the G2 boys who got into trouble most. High dishonesty was rated by peers.

\section{Risk Factors for G3 Male Offending}

Parental Convictions of the G2 father and G2 mother up to age 32 were obtained from criminal record searches. Authoritarian attitudes to parenting of G2 fathers and G2 mothers were obtained from the same Parental Attitude Schedules used with the G1 parents, completed by the G2 males and their G2 female partners when the G2 male was age 32. As for G1, young fathers referred to G2 males who were under age 23 at the time of the birth of their first child, and young mothers referred to G2 mothers who were under age 21 at the birth of their first known child. (We only have records of children that the G2 female had with the G2 male.) Anxiety/depression of the G2 father was measured using the General Health Questionnaire [29], and depression of the G2 mother was based on her reporting at least eight of the nine diagnostic criteria for major depressive disorder from the DSM-IV. (This was only available when the G2 male was age 48.)

Family Uninvolved G2 fathers were those who spent the least time in activities with their children each week (according to their reports at age 32). Physical punishment referred to the G2 father hitting or smacking his children when they were very naughty. Physical punishment was reported by both the G2 male at age 32 and by the G3 male (in retrospective questions about his childhood). Poor parental supervision referred to the G2 father not knowing where his children were when they were out, and this was also reported by the G3 male. Parental conflict was based on the G2 father's report of frequent rows, and the 
G2 father also answered about whether he had a child living elsewhere by age 32. The G3 male, in his interview, reported on whether he had lived with his G2 father for the whole time period up to his 16th birthday or whether he had been separated.

Socio-economic Low take-home pay was reported by the G2 male at age 32 . Large family size referred to five or more people living in the G2 male's household when he was age 32. Poor housing of the G2 male at age 32 was rated by the interviewer, based on whether the home was dirty, smelly, damp, neglected, overcrowded and inadequately furnished, had vermin, or had structural problems. Low social class at age 32 indicated that the G2 male had a semi-skilled or unskilled manual job.

Attainment Early school leaving was based on the report of the G3 male that he had left school before age 16 . He also reported on whether he had passed any advanced level examinations.

Impulsiveness The G3 male reported on whether he often or very often took many risks under age 12, and on whether he always had difficulty paying attention at school.

Behaviour The G3 male also reported on whether he had ever been suspended from school and on whether he had been a frequent truant (1 day per week or more).

\section{Results}

Age 8-10 Risk Factors for G2 Male Offending

Table 1 shows the strength of relationships between the age 8 and 10 risk factors and convictions of the $\mathrm{G} 2$ males up to age 21 . Three of the eight parental risk factors were significant predictors, and having a convicted G1 father was a somewhat stronger predictor than having a convicted G1 mother. Four of the five family risk factors were significant predictors: all except low G1 paternal involvement with the G2 boy. Three of the four socio-economic risk factors were significant predictors: all except low social class. All of the individual risk factors (measuring attainment, impulsiveness and behaviour) were significant predictors.

Logistic regression analyses were then carried out to investigate independent predictors. They were first of all carried out within categories of risk factors (e.g. parental or family), and the independently important variables were then included in a final logistic regression analysis. Only explanatory risk factors were studied; behavioural variables were excluded. Forward stepwise analyses were performed in order to minimize problems of multicollinearity. Table 2 shows that five risk factors were independently predictive: one parental (convicted G1 father), one family (disrupted family), one socio-economic (large family size), one attainment (low junior school 
Table 1 Age 8-10 risk factors for G2 male offending up to age 21

\begin{tabular}{|c|c|c|c|c|}
\hline Risk factor $(\%)$ & $\% \mathrm{NR}$ & $\% \mathrm{R}$ & OR & $\mathrm{CI}$ \\
\hline \multicolumn{5}{|l|}{ Parental } \\
\hline Convicted G1 father at $32(20.0)$ & 26.9 & 61.7 & 4.38 & $2.62-7.29$ \\
\hline Convicted G1 mother at 32 (7.4) & 31.8 & 60.0 & 3.21 & $1.50-6.89$ \\
\hline Authoritarian G1 father (29.3) & 29.3 & 36.9 & 1.41 & $0.77-2.60$ \\
\hline Authoritarian G1 mother (30.4) & 30.3 & 37.6 & 1.39 & $0.82-2.88$ \\
\hline Young G1 father (19.0) & 33.0 & 35.5 & 1.12 & $0.66-1.89$ \\
\hline Young G1 mother (31.1) & 31.4 & 39.2 & 1.41 & $0.91-2.19$ \\
\hline Nervous G1 father (21.5) & 31.7 & 39.7 & 1.42 & $0.85-2.38$ \\
\hline Nervous G1 mother (32.4) & 29.6 & 39.8 & 1.58 & $1.01-2.47$ \\
\hline \multicolumn{5}{|l|}{ Family } \\
\hline Uninvolved G1 father (28.0) & 30.8 & 39.0 & 1.44 & $0.85-2.45$ \\
\hline Harsh discipline (29.2) & 29.0 & 42.9 & 1.83 & $1.16-2.89$ \\
\hline Poor supervision (19.1) & 28.6 & 51.4 & 2.64 & $1.56-4.46$ \\
\hline Parental conflict (24.0) & 28.1 & 46.6 & 2.24 & $1.37-3.67$ \\
\hline Disrupted family (22.3) & 29.0 & 51.1 & 2.56 & $1.59-4.14$ \\
\hline \multicolumn{5}{|l|}{ Socio-economic } \\
\hline Low family income (23.0) & 29.3 & 49.5 & 2.37 & $1.47-3.80$ \\
\hline Large family size (24.3) & 28.8 & 50.0 & 2.48 & $1.55-3.95$ \\
\hline Poor housing (37.1) & 27.6 & 44.7 & 2.12 & $1.39-3.24$ \\
\hline Low social class (19.6) & 32.3 & 40.5 & 1.43 & $0.86-2.37$ \\
\hline \multicolumn{5}{|l|}{ Attainment } \\
\hline Low nonverbal IQ (25.2) & 29.5 & 47.1 & 2.13 & $1.34-3.37$ \\
\hline Low verbal IQ (25.2) & 30.3 & 44.6 & 1.85 & $1.16-2.93$ \\
\hline Low attainment (23.7) & 28.3 & 52.2 & 2.77 & $1.71-4.51$ \\
\hline \multicolumn{5}{|l|}{ Impulsiveness } \\
\hline High daring (29.9) & 26.0 & 53.3 & 3.26 & $2.08-5.09$ \\
\hline High impulsivity (25.5) & 30.6 & 43.7 & 1.76 & $1.11-2.79$ \\
\hline High hyperactivity (20.1) & 30.4 & 48.1 & 2.12 & $1.29-3.49$ \\
\hline \multicolumn{5}{|l|}{ Behaviour } \\
\hline High troublesomeness (22.3) & 26.4 & 60.0 & 4.17 & $2.56-6.82$ \\
\hline High dishonesty (25.2) & 28.0 & 50.0 & 2.58 & $1.57-4.24$ \\
\hline
\end{tabular}

$\% R \%$ convicted of risk category, $\% N R \%$ convicted of non-risk category, $O R$ odds ratio, $C I 95 \%$ confidence interval

$N=404$ (maximum)

attainment) and one impulsiveness (high daring). (Large family size is included here although it was not quite significant on a two-tailed test. One-tailed tests are quite justifiable here in light of the directional predictions.) Numerous prior analyses of the CSDD have found that about five risk factors at age 8-10, typically drawn from different categories, are independent predictors of later G2 offending (e.g. [17]). 
Table 2 Logistic regression analysis predicting G2 male offending up to age 21

\begin{tabular}{lllll}
\hline Risk factor & LRCS change & $p$ & Partial OR & $p$ \\
\hline Convicted G1 father at 32 & 33.80 & .0001 & 2.82 & .0005 \\
High daring & 20.29 & .0001 & 2.94 & .0001 \\
Low attainment & 11.19 & .0008 & 2.25 & .004 \\
Disrupted family & 5.07 & .024 & 1.96 & .023 \\
Large family size & 3.35 & .067 & 1.69 & .065 \\
\hline
\end{tabular}

LRCS likelihood ratio chi-square, $O R$ odds ratio

$p$ values two-tailed; $N=377$ (actual)

\section{Risk Factors for G3 Male Offending}

Table 3 shows the strength of relationships between risk factors and convictions of the G3 males up to age 21. ${ }^{1}$ Of the parental risk factors, a convicted G2 father and a convicted G2 mother were significant predictors. As with the G1 parents, G2 parental authoritarianism and young parents were not predictive of G3 offending. Four of the family risk factors were significantly related: poor supervision according to both the G2 male at age 32 and the G3 male, physical punishment reported by the G3 male and separation from a G2 parent before age 16 according to the G3 male.

All of the socio-economic risk factors at age 32, including low social class of the G2 father, were significantly predictive of G3 offending. Both of the G3 attainment risk factors, together with early risk taking, suspension and frequent truancy, were related to G3 offending. Poor attention at school was not related to G3 offending.

Table 4 shows the results of a logistic regression analysis predicting G3 male offending. As before, the behavioural variables were excluded. The strongest independent predictors were a convicted G2 father (a parental risk factor), risk-taking under age 12 (measuring impulsiveness), low G2 take-home pay (a socio-economic factor) and

\footnotetext{
${ }^{1} 1$. Because all the children are not all independent, it is necessary to adjust the variance of the odds ratio to take account of the clustering of children in families. It is easiest to do this by referring to the standardized mean difference $d$. Clustering has no material effect on the value of $d$ but it increases the variance of $d$ (see, e.g. [30]). The variance is increased by $[1+(n-1) * \mathrm{ICC}]$, where $n$ is the number of individuals in a cluster and ICC is the intraclass correlation. This correction has been known for many years and has been called the design effect (e.g. [32]) or the variance inflation factor (e.g. [7]).

It is well known (see e.g. [33], p. 202) that

$$
\begin{aligned}
& \operatorname{Ln}(\mathrm{OR})=\pi * d / \operatorname{sqrt}(3) \\
& \text { or } \operatorname{Ln}(\mathrm{OR})=1.81 * d \\
& \text { Therefore, } \operatorname{SE}[\operatorname{Ln}(\mathrm{OR})]=1.81 * \operatorname{SE}(d)
\end{aligned}
$$

Since SE [Ln (OR)] increases in direct proportion to $\mathrm{SE}(d)$, it follows that the variance of $\operatorname{Ln}(\mathrm{OR})$, like the variance of $d$, needs to be increased by $[1+(\mathrm{n}-1) * \mathrm{ICC}]$ to take account of clustering. For the dichotomized measure of conviction, the ICC was .37 , indicating a considerable degree of clustering of convictions in families. Since there were 344 boys in 220 families, the average number of boys in a family was 1.56. Therefore, the variance of $\mathrm{Ln}(\mathrm{OR})$ was increased by [1+0.56*0.37], or by $21 \%$, to take account of the clustering of convictions. This is equivalent to increasing the standard error of $\operatorname{Ln}(\mathrm{OR})$ by $10 \%$.
} 
Table 3 Risk factors for G3 male offending up to age 21

\begin{tabular}{|c|c|c|c|c|}
\hline Risk factor (\%) & $\% \mathrm{NR}$ & $\% \mathrm{R}$ & OR & \\
\hline \multicolumn{5}{|l|}{ Parental } \\
\hline Convicted G2 father at 32 (41.0) & 13.3 & 30.5 & 2.86 & $1.58-5.19$ \\
\hline Convicted G2 mother at $32(9.8)$ & 19.1 & 43.3 & 3.23 & $1.37-7.64$ \\
\hline Authoritarian G2 father at 32 (30.1) & 21.1 & 19.6 & 0.91 & $0.48-1.73$ \\
\hline Authoritarian G2 mother at 32 (30.7) & 22.4 & 20.8 & 0.91 & $0.44-1.87$ \\
\hline Young G2 father (28.5) & 20.3 & 20.4 & 1.01 & $0.53-1.90$ \\
\hline Young G2 mother (23.0) & 19.3 & 23.7 & 1.30 & $0.66-2.55$ \\
\hline Depressed G2 father at $32(18.0)$ & 21.2 & 18.0 & 0.82 & $0.37-1.79$ \\
\hline Depressed G2 mother at 48 (35.3) & 14.4 & 21.5 & 1.63 & $0.69-3.86$ \\
\hline \multicolumn{5}{|l|}{ Family } \\
\hline Uninvolved G2 father at 32 (18.1) & 19.3 & 19.1 & 0.99 & $0.41-2.39$ \\
\hline Physical punishment at 32 (37.7) & 17.6 & 25.0 & 1.56 & $0.80-3.04$ \\
\hline Physical punishment from G3 (33.3) & 15.6 & 32.2 & 2.58 & $1.34-4.98$ \\
\hline Poor supervision at 32 (25.5) & 15.0 & 28.1 & 2.22 & $1.06-4.68$ \\
\hline Poor supervision from G3 (48.6) & 11.3 & 30.6 & 3.47 & $1.72-7.00$ \\
\hline Parental conflict at 32 (33.0) & 19.0 & 19.8 & 1.05 & $0.54-2.04$ \\
\hline Separated from child at 32 (22.9) & 19.2 & 26.8 & 1.53 & $0.78-3.02$ \\
\hline Separated from child from G3 (25.6) & 16.9 & 31.9 & 2.30 & $1.15-4.58$ \\
\hline \multicolumn{5}{|l|}{ Socio-economic } \\
\hline Low take-home pay at 32 (19.4) & 13.5 & 33.3 & 3.20 & $1.54-6.66$ \\
\hline Large family size at 32 (26.5) & 16.9 & 31.1 & 2.23 & $1.21-4.10$ \\
\hline Poor housing at 32 (27.5) & 15.8 & 37.7 & 3.23 & $1.68-6.22$ \\
\hline Low social class at 32 (19.8) & 17.2 & 30.3 & 2.10 & $1.07-4.12$ \\
\hline \multicolumn{5}{|l|}{ Attainment } \\
\hline Early school leaving from G3 (13.5) & 16.4 & 48.6 & 4.83 & $2.16-10.79$ \\
\hline No A level from G3 (66.9) & 9.9 & 26.1 & 3.22 & $1.39-7.44$ \\
\hline \multicolumn{5}{|l|}{ Impulsiveness } \\
\hline Risk taking under 12 from G3 (29.3) & 14.4 & 35.8 & 3.33 & $1.71-6.47$ \\
\hline Poor attention at school from G3 (13.4) & 19.2 & 29.7 & 1.78 & $0.76-4.16$ \\
\hline \multicolumn{5}{|l|}{ Behaviour } \\
\hline Suspended from school from G3 (27.5) & 13.0 & 40.8 & 4.61 & $2.34-9.07$ \\
\hline Frequent truant from G3 (23.2) & 14.6 & 40.6 & 3.99 & $2.00-7.97$ \\
\hline
\end{tabular}

$\% R \%$ convicted of risk category, $\% N R \%$ convicted of non-risk category, $O R$ odds ratio, $C I 95 \%$ confidence Interval

$N=344$ (maximum)

three family factors (physical punishment, poor supervision and separation). All six risk factors were originally significant in the analysis, but only two were significant on a two-tailed test after the variance inflation factor described in Note 1 was applied.

In order to obtain a quantitative measure of the similarity of risk factors in the two generations, effect sizes for $\mathrm{G} 2$ offending were correlated with effect sizes for $\mathrm{G} 3$ offending 
Table 4 Logistic regression analysis predicting G3 male offending up to age 21

\begin{tabular}{lcccc}
\hline Risk factor & LRCS change & $p$ & Partial OR & $p$ \\
\hline Convicted G2 father at 32 & 13.45 & .0002 & 2.06 & .085 \\
Risk taking under 12 from G3 & 8.32 & .004 & 2.30 & .051 \\
Low take-home pay at 32 & 6.02 & .014 & 2.20 & .093 \\
Physical punishment from G3 & 5.12 & .024 & 2.50 & .028 \\
Poor supervision from G3 & 4.83 & .028 & 2.47 & .035 \\
Separated from child from G3 & 4.10 & .043 & 2.25 & .063 \\
\hline
\end{tabular}

LRCS likelihood ratio chi-square, $O R$ odds ratio

$p$ values two-tailed; $N=235$ (actual)

over 20 similar risk factors. Because the ORs are ratio variables, the effect sizes were Ln (OR), which is an interval scale variable. Where there were both G2 and G3 effect sizes (for physical punishment, poor supervision and separation), these were averaged. Remarkably, the correlation between effect sizes was $r=.80(p<.0001)$, and the mean effect sizes for $\mathrm{G} 2$ and $\mathrm{G} 3$ offending were similar $(\mathrm{OR}=2.09$ for $\mathrm{G} 2$ and $\mathrm{OR}=1.93$ for $\mathrm{G} 3)$. The $\mathrm{G} 2$ and $\mathrm{G} 3$ effect sizes were significantly different only for parental conflict $(z=2.56, p=.010)$.

\section{Discussion}

Of the parental risk factors, convicted fathers and convicted mothers were important for both G2 and G3 offending. Authoritarian parental attitudes were not important. This may be because the parental attitude questionnaire became increasingly out of date, and authoritarian parental attitudes decreased considerably over time [38]. A young mother or father was not a significant predictor of offending, contrary to previous findings [35]. Nervousness or depression of parents was not very important for offending, although it was previously found to be an important predictor of psychopathy [13].

Of the family risk factors, poor supervision and disrupted families were important for both G2 and G3 offending. Low paternal involvement with the child was not important for either G2 or G3 offending. Harsh discipline was important for G2 and physical punishment was important for G3 (according to G3 males). The G2 risk factor included a cold attitude as well as harsh discipline. Parental conflict was important for G2 but not for G3. This may be because the earlier risk factor reflected more extreme conflicts, in an era when divorce was rare. The later risk factor reflected rows between parents, but G2 parents with the most extreme conflicts may already have been divorced. In general, the family risk factors for G3 offending were problematic because the information came from the father rather than from the mother, because the father at age 32 was answering for his children in general rather than for the specific G3 male, and because the G2 father may sometimes have been separated from the G3 male.

Of the socio-economic factors, low family income, large family size and poor housing were important for both G2 and G3 offending. However, the two variables measuring family size were not very comparable, as family size in the earlier time period referred to the number of children born to the G1 mother, whereas family size in 
the later time period referred to the number of people in the G2 male's household. Low social class was important for G3 offending but not for G2 offending. This may have been because, for the G1 males, some unskilled manual jobs had relatively high wages, whereas this was less true for the G2 males. Indeed, the OR between low income and low social class was significantly greater (5.66) in the later time period than in the earlier time period $(2.95 ; z=2.15, p=.032)$.

Of the individual risk factors, measures of attainment and impulsiveness were important for both G2 and G3 offending. Unlike the earlier prospective measures, the G3 measures were obtained retrospectively from the G3 males. Therefore, the analysis of risk factors for $\mathrm{G} 3$ males is not always strictly predictive.

The logistic regression analyses (as with previous comparable analyses) indicated that one risk factor from each of five categories independently predicted G2 offending. One risk factor from four categories independently predicted G3 offending, but family factors were relatively more important. All these results should be the starting point for formulating and testing developmental theories of offending (see [23]).

Summarizing the main results, risk factors for $\mathrm{G} 2$ offending were highly correlated $(r=.80)$ with risk factors for G3 offending. Eleven risk factors were significant predictors of both G2 and G3 offending: a convicted father, a convicted mother, harsh discipline, poor parental supervision, a disrupted family, low family income, large family size, poor housing, low attainment, daring/risk-taking and antisocial child behaviour. A nervous/depressed mother was marginally significant for G2 offending but not significant for G3 offending. Several risk factors were not significant predictors of either G2 or G3 offending: authoritarian parents, young parents, a nervous/depressed father, and an uninvolved father. The findings were markedly different for only three risk factors: parental conflict (the only significant difference between G2 and G3), low social class and hyperactivity/attention problems.

While we did our best to measure comparable risk factors in the different generations, it has to be admitted that some risk factors were not very comparable. For example, hyperactivity in G2 was not the same as attention problems in G3. More efforts are needed to investigate the replicability of risk factors (and protective factors) over time and place. To the extent that risk factors are replicable in successive generations, this helps to answer objections that results obtained in one time period are not relevant to a later time period. Where results vary in different time periods, it is important to investigate cohort or time period effects that might explain the differences. In our comparisons, we conclude that most of the findings in one generation were remarkably replicable in the next generation.

Acknowledgments For funding the Cambridge Study in Delinquent Development, we are very grateful to the Home Office, the Department of Health, the Department for Education, the Rayne Foundation, the Barrow Cadbury Trust and the Smith-Richardson Foundation.

\section{References}

1. Bailey, J. A., Hill, K. G., Oesterle, S., \& Hawkins, J. D. (2009). Parenting practices and problem behavior across three generations: monitoring, harsh discipline, and drug use in the intergenerational transmission of externalizing behavior. Developmental Psychology, 45, 1214-1226. 
2. Belsky, J., Conger, R., \& Capaldi, D. M. (2009). The intergenerational transmission of parenting: introduction to the special section. Developmental Psychology, 45, 1201-1204.

3. Bijleveld, C. C. J. H., \& Farrington, D. P. (2009). Editorial: the importance of studies of intergenerational transmission of antisocial behaviour. Criminal Behaviour and Mental Health, 19, 77-79.

4. Capaldi, D. M., Conger, R. D., Hops, H., \& Thornberry, T. P. (2003). Introduction to special section on three-generation studies. Journal of Abnormal Child Psychology, 31, 123-125.

5. Capaldi, D. M., Pears, K. C., Patterson, G. R., \& Owen, C. D. (2003). Continuity of parenting practices across generations in an at-risk sample: a prospective comparison of direct and mediated associations. Journal of Abnormal Child Psychology, 31, 127-142.

6. Cohen, P., Slomkowski, C., \& Robins, L. N. (Eds.). (1999). Historical and geographical influences on psychopathology. Mahwah: Lawrence Erlbaum.

7. Donner, A., Birkett, N., \& Buck, C. (1981). Randomization by cluster. American Journal of Epidemiology, 114, 906-914.

8. Elder, G. H. (1998). The life course as developmental theory. Child Development, 69, 1-12.

9. Elliott, D. S., Huizinga, D., \& Menard, S. (1989). Multiple problem youth: Delinquency, substance use, and mental health problems. New York: Springer.

10. Farrington, D. P. (1989). Later adult life outcomes of offenders and non-offenders. In M. Brambring, F. Losel, \& H. Skowronek (Eds.), Children at risk: Assessment, longitudinal research, and intervention (pp. 220-244). Berlin, Germany: De Gruyter.

11. Farrington, D. P. (1995). The development of offending and antisocial behaviour from childhood: key findings from the Cambridge study in delinquent development. Journal of Child Psychology and Psychiatry, 36, 929-964.

12. Farrington, D. P. (2003). Key results from the first 40 years of the Cambridge study in delinquent development. In T. P. Thornberry \& M. D. Krohn (Eds.), Taking stock of delinquency: An overview of findings from contemporary longitudinal studies (pp. 137-183). New York: Kluwer/Plenum.

13. Farrington, D. P. (2007). Social origins of psychopathy. In A. Felthous \& H. Sass (Eds.), The international handbook of psychiatric disorders and the law (pp. 319-334). Chichester: Wiley.

14. Farrington, D. P., Barnes, G., \& Lambert, S. (1996). The concentration of offending in families. Legal and Criminological Psychology, 1, 47-63.

15. Farrington, D. P., Coid, J. W., Harnett, L. M., Jolliffe, D., Soteriou, N., Turner, R. E., \& West, D. J. (2006). Criminal careers up to age 50 and life success up to age 48: New findings from the Cambridge Study in Delinquent Development. London: Home Office (Research Study No. 299).

16. Farrington, D. P., Coid, J. W., \& Murray, J. (2009). Family factors in the intergenerational transmission of offending. Criminal Behaviour and Mental Health, 19, 109-124.

17. Farrington, D. P., Coid, J. W., \& West, D. J. (2009). The development of offending from age 8 to age 50: recent results from the Cambridge study in delinquent development. Monatsschrift fur Kriminologie und Strafrechtsreform (Journal of Criminology and Penal Reform), 92, 160-173.

18. Farrington, D. P., \& Jolliffe, D. (2005). Crime and punishment in England and Wales, 1981-1999. In M. Tonry \& D. P. Farrington (Eds.), Crime and punishment in Western countries, 1980-1999 (pp. 41-81). Chicago: University of Chicago Press.

19. Farrington, D. P., Lambert, S., \& West, D. J. (1998). Criminal careers of two generations of family members in the Cambridge study in delinquent development. Studies on Crime and Crime Prevention, 7 , 85-106.

20. Farrington, D. P., \& Loeber, R. (1999). Transatlantic replicability of risk factors in the development of delinquency. In P. Cohen, C. Slomkowski, \& L. N. Robins (Eds.), Historical and geographical influences on psychopathology (pp. 299-329). Mahwah: Lawrence Erlbaum.

21. Farrington, D. P., \& Loeber, R. (2000). Some benefits of dichotomization in psychiatric and criminological research. Criminal Behaviour and Mental Health, 10, 100-122.

22. Farrington, D. P., Piquero, A. R., \& Jennings, W. G. (2013). Offending from childhood to late middle age: Recent results from the Cambridge study in delinquent development. New York: Springer.

23. Farrington, D. P., \& Ttofi, M. M. (2015). Developmental and life-course theories of offending. In J. Morizot \& L. Kazemian (Eds.), The development of criminal and antisocial behavior: Theory, research and practical applications (pp. 19-38). New York: Springer.

24. Farrington, D. P., Ttofi, M. M., Crago, R. V., \& Coid, J. W. (2014). Prevalence, frequency, onset, desistance and criminal career duration in self-reports compared with official records. Criminal Behaviour and Mental Health, 24, 241-253.

25. Farrington, D. P., \& West, D. J. (1981). The Cambridge study in delinquent development (United Kingdom). In S. A. Mednick \& A. E. Baert (Eds.), Prospective longitudinal research (pp. 137-145). Oxford, UK: Oxford University Press. 
26. Farrington, D. P., \& West, D. J. (1990). The Cambridge study in delinquent development: A long-term follow-up of 411 London males. In H.-J. Kerner \& G. Kaiser (Eds.), Kriminalitat:Personlichkeit, lebensgeschichte und verhalten (Criminality: Personality, behavior and life history) (pp. 115-138). Berlin: Springer.

27. Gibson, H. B. (1968). The measurement of parental attitudes and their relation to boys' behaviour. British Journal of Educational Psychology, 38, 233-239.

28. Gibson, H. B., Hanson, R., \& West, D. J. (1967). A questionnaire measure of neuroticism using a shortened scale derived from the cornell medical index. British Journal of Social \& Clinical Psychology, 6, 129-136.

29. Goldberg, D. P. (1972). The detection of psychiatric illness by questionnaire. London: Oxford University Press.

30. Hedges, L. V., \& Hedberg, E. C. (2007). Intraclass correlations for planning group randomized experiments in rural education. Journal of Research in Rural Education, 22, 1-15.

31. Johnson, M. C., Morris, R. G., \& Menard, S. (2015). Historical invariance in delinquency causation: a test of equivalent models of delinquency for two generations of adolescents. Crime and Delinquency.

32. Kish, L. (1965). Survey sampling. New York: Wiley.

33. Lipsey, M. W., \& Wilson, D. B. (2001). Practical meta-analysis. Thousand Oaks: Sage.

34. Menard, S., \& Johnson, M. C. (2015). An intergenerational test of integrated theory. Deviant Behavior, 36, $87-100$

35. Nagin, D. S., Pogarsky, G., \& Farrington, D. P. (1997). Adolescent mothers and the criminal behavior of their children. Law and Society Review, 31, 137-162.

36. Piquero, A. R., Farrington, D. P., \& Blumstein, A. (2007). Key issues in criminal career research: New analyses of the Cambridge study in delinquent development. Cambridge: Cambridge University Press.

37. Serbin, L. A., \& Stack, D. M. (1998). Introduction to the special section: studying intergenerational continuity and the transfer of risk. Developmental Psychology, 34, 1159-1161.

38. Smith, C. A., \& Farrington, D. P. (2004). Continuities in antisocial behaviour and parenting across three generations. Journal of Child Psychology and Psychiatry, 45, 230-247.

39. Thornberry, T. P., Freeman-Gallant, A., Lizotte, A. J., Krohn, M. D., \& Smith, C. A. (2003). Linked lives: the intergenerational transmission of antisocial behavior. Journal of Abnormal Child Psychology, 31, 171184.

40. West, D. J. (1969). Present conduct and future delinquency. London: Heinemann.

41. West, D. J. (1982). Delinquency: Its roots, careers and prospects. London: Heinemann.

42. West, D. J., \& Farrington, D. P. (1973). Who becomes delinquent? London: Heinemann.

43. West, D. J., \& Farrington, D. P. (1977). The delinquent way of life. London: Heinemann. 